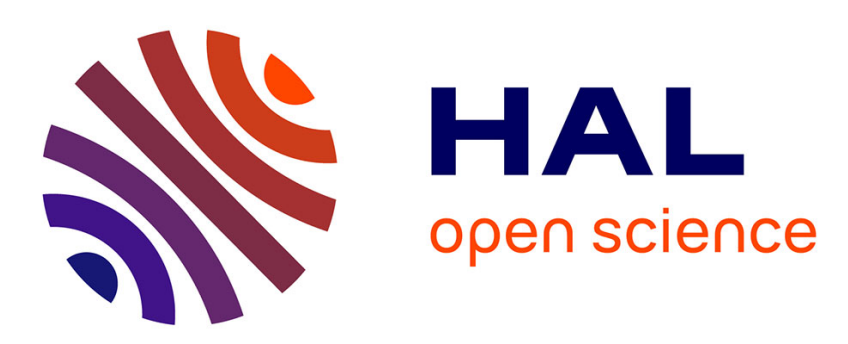

\title{
Design and microfabrication of a lateral excited gallium arsenide biosensor
}

\author{
A. Bienaime, L. Liu, C. Elie-Caille, T. Leblois
}

\section{To cite this version:}

A. Bienaime, L. Liu, C. Elie-Caille, T. Leblois. Design and microfabrication of a lateral excited gallium arsenide biosensor. European Physical Journal: Applied Physics, 2012, 57 (2), 10.1051/epjap/2011110111 . hal-00768706

\section{HAL Id: hal-00768706 \\ https://hal.science/hal-00768706}

Submitted on 23 Dec 2012

HAL is a multi-disciplinary open access archive for the deposit and dissemination of scientific research documents, whether they are published or not. The documents may come from teaching and research institutions in France or abroad, or from public or private research centers.
L'archive ouverte pluridisciplinaire HAL, est destinée au dépôt et à la diffusion de documents scientifiques de niveau recherche, publiés ou non, émanant des établissements d'enseignement et de recherche français ou étrangers, des laboratoires publics ou privés. 


\title{
Design and microfabrication of a lateral excited gallium arsenide biosensor
}

\author{
A.Bienaime, L. Liu, C. Elie-Caille and T. Leblois ${ }^{\mathrm{a}}$ \\ FEMTO-ST Institute \\ 32 avenue de l'Observatoire, 25044 Besançon cedex, France
}

Alex Bienaimé : Tel +336623850 11, Fax + 33381853998

E-mail:alex.bienaime@femto-st.fr

Celine Elie-Caille : Tel : +33 3818539 22, Fax + 33381853998

E-mail : celine.caille@femto-st.fr

${ }^{\mathrm{a} C}$ Corresponding author:

Thérèse Leblois : Tel: +33 3818539 74, Fax + 33381853998

E-mail: therese.leblois@femto-st.fr 


\begin{abstract}
GaAs crystal presents some interesting perspectives for resonant biosensors due to its piezoelectric and good mechanical properties and the opportunity to bio-functionalize the surface. Moreover, GaAs can be micromachined by wet etching in several solutions, which constitutes a batch and low-cost process of fabrication. The lateral field excitation (LFE) is used to generate bulk acoustic waves. The main advantage of LFE is the possibility to measure in liquid media, but moreover reduced aging and increased frequency stability are also ensured. In this study, an analytical modelisation is used to determine the orientations of the vibrating membrane and the electric field that give satisfactory metrological performances. Electrical performances are discussed as a function of geometrical parameters. A simulation based on a Finite Element Modelisation is performed in order to optimize the design of the resonant structure. The microfabrication process of the structure is presented. The choice of etchants is discussed in terms of etch rates and surface textures. Several steps of the fabrication of the sensing area structure are shown and characterized. Finally, the active area is fabricated according to the theoretical and experimental results of this study.
\end{abstract}




\section{Introduction}

Piezoelectric devices are highly attractive for biosensor applications due to their high sensitivity and stability [1-4]. Several materials are used and, up to now, quartz crystal remains the reference material [3-6] for bulk acoustic wave and surface acoustic wave resonators (QCM) with high stability. High quality quartz crystals can be found easily. The micromachining of quartz structures is well known and several microcantilevers or disks have been fabricated in specific plates such as Z and AT cuts [7]; But a batch process of microfabrication in non-conventional cuts remains uneasy $[8,9]$ because anisotropic wet etching gives often rise to curved facets and rounded shapes. Semi-insulator gallium arsenide (GaAs) crystals constitute a good example of materials that combine piezoelectric properties and advanced MEMS technologies [10-18]. In fact, several technologies to fabricate GaAs microstructures like cantilevers, bridges, diaphragms and membranes, have been developed by several authors. We distinguish surface and bulk micromachining processes. The bulk micromachining processes include wet etching, reactive ion etching (RIE) or both to perform microstructures. Bulk micromachined structures made using wet etching are strongly dependent on directional properties of the wet chemistry of the crystal. This technology is supplanted by the RIE to fabricate high aspect ratio microstructures. The SCREAM process [15] which combines wet and dry etching has been developed on GaAs to fabricate deep highaspect-ratio nested structures including high force actuators and large sensing capacitances for scanned probe instruments applications. This SCREAM process, which includes several successive steps, remains too complicated for our application. We have to keep in mind that the aim of our sensor is to fabricate the sensing area using a low-cost batch process. The wet chemical etching seems to be the more appropriate technology for our application. To micromachine GaAs structures by wet etching, etch stop layers are commonly used [16-18]. Nevertheless, the sensor we design uses piezoelectric transduction. We have to keep a semiinsulating membrane of GaAs. A technology based on deep implantation of nitrogen ions into n-type GaAs substrates following by an annealing at $600^{\circ} \mathrm{C}$ has been developed $[17,18]$. This last step allows the conversion of the implanted layer to a semi-insulated GaAs layer. This powerful technology enables the fabrication of thin membranes after selective chemical etching steps. It seems limited to a few $\mu \mathrm{m}$ thick membranes. Consequently, taking into account of the membrane geometry we plan to fabricate, we focus our study on the wet etching without etch stop layer.

Moreover, some authors investigated the possibility to bio-functionalize this material with thiolates or silane molecules [19-20]. So GaAs can be also considered as a promising material for resonant bioMEMS. The aim of this work is then to design new GaAs biosensors that fulfil the following requirements:

(i) Piezoelectric excitation of the bulk acoustic wave GaAs structure

(ii) Design of a resonant structure allowing measurements in liquid media.

(iii) Microfabrication of the resonant structure by wet micromachining.

The first part of this paper is then devoted to the design of a resonant structure used in liquid media and the determination of the orientations of both substrate and electric field that allow the excitation of bulk waves in the substrate. Metrological parameters such as impedance and $\mathrm{Q}$ factor are evaluated according to geometrical parameters. The study is performed using analytical and numerical simulations. The second part deals with the microfabrication of the resonator using several experimental conditions. A final micromachined structure is then carried out by combining results of parts 1 and 2 . 


\section{Design of the resonant structure}

A piezoelectric plate can be driven by thickness field excitation (TFE) or lateral field excitation (LFE). LFE offers some advantages over TFE such as a higher Q value and an increase in the frequency stability due to a vibration motion free of electrodes. Moreover, LFE enables some modes that are not available by TFE to be driven. The structure design must take into account the fact that the measurements will have to take place in liquid media. The isolation of the electrical parts of the sensors with liquid media remains the main advantage of LFE. Consequently, the schematic diagram of the sensor structure could be given by Fig. 1 .

Fig. 1.

In the following section, we determine the orientations of the substrate and the electric field that allow the excitation of a bulk acoustic wave in the GaAs membrane.

\subsection{Piezoelectric excitation: Theory}

To find the best orientations of substrate and electric field, we use the Christoffel-Beckmann method [21-23]. This analytical method allows the determination of the electromechanical coupling coefficient of the resonator for the three shear modes, as explained in the following steps. To respect the hypothesis of the method, we assume that the dimensions of length $\ell$ and width $w$ of the membrane are great with respect to the thickness $t$. The study is driven in the general case of a doubly rotated wafer and any orientation of electrodes in the plane of the substrate. To perform the calculation, we introduce the three angles of rotation $(\varphi, \theta, \psi)$. Starting with the reference plane (100) and the reference coordinate system called $\left(\mathrm{O}, \mathrm{x}_{1}, \mathrm{x}_{2}\right.$, $\mathrm{x}_{3}$ ) (the reference axes coincide with the $\langle 100\rangle,\langle 010\rangle$ and $\langle 001\rangle$ directions respectively), we define the rotated axes $x^{*}$ and $x^{*}{ }_{3}$ corresponding to the wafer orientation. As seen in Fig. $2 \mathrm{~A}$, the orientation of the substrate is given by the angles $(\varphi, \theta)$ according to the IEEE standard on piezoelectricity [24]. The final $\mathrm{x}_{1}{ }_{1}$ and $\mathrm{x}_{3}{ }_{3}$ axes are obtained by a third rotation $\psi$ about the $\mathrm{x}_{2}{ }_{2}$ axis and one of the direction of alignment of the rectangular membrane in the $(0$, $\mathrm{x}_{1}, \mathrm{x}_{3}$ ) plane lies parallel to the $\mathrm{x}_{1}{ }_{1}$ axis (Fig. 2B) The direction of the electric field, which is defined by the angle $\psi$ also lies parallel to the $\mathrm{x}^{\prime}{ }_{1}$ direction (Fig. $2 \mathrm{C}$ ).

Fig. 2.

In a piezoelectric material, the local equation of equilibrium can be written as following:

$$
\left\{\begin{array}{l}
T_{i j, i}^{\prime}+F_{j}^{\prime}=\rho \ddot{u}_{j}^{\prime} \\
D_{i, i}^{\prime}=0
\end{array}\right.
$$

where $T^{\prime}{ }_{i j}$ are the components of the incremental stress tensor, $D$ ' the incremental electric displacement vector, $F$ ' the force per volume unit, $\rho$ the mass density and $u^{\prime}$ the wave displacement vector. The superscript indicates that the equations are expressed in the rotated coordinates system $\left(\mathrm{x}_{1}{ }_{1}, \mathrm{x}_{2}, \mathrm{x}_{3}{ }_{3}\right)$.

Introducing the piezoelectric equations in (1) and assuming that $F^{\prime}=0$, that $E$ is applied along $\mathrm{x}_{1}{ }_{1}$ axis and that the displacement $u$ ' depends only on the $\mathrm{x}_{2}{ }_{2}$ coordinate, we obtain the constitutive equations (2): 


$$
\left\{\begin{array}{l}
\rho \ddot{u}_{j}^{\prime}=C_{2 j k 2}^{\prime} u_{k, 22}^{\prime}+e_{12 j}^{\prime} \phi_{, 12} \\
0=e_{2 k 2}^{\prime} u_{k, 22}^{\prime}-\varepsilon_{21}^{\prime} \phi_{, 12}
\end{array}\right.
$$

where $C^{\prime}{ }_{i j k l}, e^{\prime}{ }_{i j k}, \varepsilon^{\prime}{ }_{i j}$ are the rotated components of the elastic, piezoelectric and dielectric tensors respectively. The displacement and the electrical potential $\Phi$ characterize the general form of the elastic wave propagating along the thickness of the plate. For each mode called $\mu$ $(\mu=\mathrm{a}, \mathrm{b}$ and $\mathrm{c}), u$ is expressed in term of frequency $f$ and velocity of waves $V^{(\mu)}$ as:

$$
u_{\alpha}=u_{\alpha}^{(\mu)} \exp \left\{j 2 \pi f\left(t-\frac{x_{2}^{\prime}}{V^{(\mu)}}\right)\right\}
$$

where $\alpha=1,2$ and 3

Equation (2) leads to (4)

$$
\rho \ddot{u}_{j}^{\prime}=\left[C_{2 j k 2}^{\prime}+\frac{e_{22 j}^{\prime} e_{2 k 2}^{\prime}}{\varepsilon_{21}^{\prime}}\right] u_{k, 22}^{\prime}
$$

and to the following eigenvalue problem (5):

$$
\left\{\left[C_{2 j k 2}^{\prime}+\frac{e_{22 j}^{\prime} e_{2 k 2}^{\prime}}{\varepsilon_{21}^{\prime}}\right]-\rho V^{(\mu)^{2}} \delta_{j k}\right\} u_{j}^{(\mu)}=0
$$

The determinant of (5) which must be equal to zero leads to the determination of stiffened eigenvalues $\lambda(\mu)=\rho V^{(\mu) 2}$ and eigenvectors $u^{(\mu)}$.

The electromechanical coupling coefficient $k^{(\mu)}$ which is the most important practical quantity associated with the vibrational modes is defined by a ratio of energies (6):

$$
\boldsymbol{k}^{(\mu)}=\frac{\boldsymbol{U}_{\boldsymbol{m}}}{\sqrt{U_{\text {ela }} U_{D}}}
$$

where $U_{\text {ela }}=\frac{1}{2} s^{E} T$ is the mechanical energy, $U_{D}=\frac{1}{2} \varepsilon^{T} E^{2}$ is the electrical energy and $U_{m}=d T E$ is the transformed energy.

The expression of $k^{(\mu)}$ versus piezoelectric, dielectric and elastic coefficients is obtained considering the $(43 m)$ symmetry of the crystal.

As usual, the resonant frequency $f_{R}$ is deduced from the dispersion equation [21]:

$$
\left(2 \pi f_{R}\right)^{2}=\frac{n^{2} \pi^{2}}{t^{2}} V^{(\mu)^{2}}\left(1-\frac{8 k^{(\mu)^{2}}}{n^{2} \pi^{2}}\right)
$$

where $\mathrm{n}$ is the partial rank.

\subsection{Piezoelectric excitation: Results}

Let be considered four different orientations of cuts that can be considered as "commercial" cuts and let us recall that GaAs crystal belongs to the $(43 \mathrm{~m})$ crystal class with the following constant set in the reference system:

$$
\begin{aligned}
& e_{14}=-0.16 \mathrm{C} / \mathrm{m}^{2} \\
& C_{11}=11.8810^{10} \mathrm{~N} / \mathrm{m}^{2}, C_{12}=5.3810^{10} \mathrm{~N} / \mathrm{m}^{2}, C_{44}=5.9410^{10} \mathrm{~N} / \mathrm{m}^{2} \\
& \varepsilon_{11}=9.7310^{(-11)} \mathrm{F} / \mathrm{m}
\end{aligned}
$$


The four wafer orientations studied here are: (100), (110), (111) and (211). For these cuts, the angle $\psi=0^{\circ}$ indicates the $\langle 110\rangle$ direction.

Fig. 3 shows the evolution of the electromechanical coupling coefficients $k^{(a)}, k^{(b)}$ and $k^{(c)}$ associated to the three modes with $\psi$. (a), (b) and (c) are respectively the quasi-longitudinal, the fast quasi-shear and the slow quasi-shear modes of vibration.

Fig. 3.

The results bring us some general comments:

(i) These plots are symmetric around $\psi=0^{\circ}$, which reflects the symmetry of the wafers around the $\langle 110\rangle$ axis.

(ii) For the (211) cut, all three modes are driven.

(iii) It is found that the pure quasi-longitudinal mode can be excited in the (110) plane whatever the considered orientation of electric field (except $\psi=0^{\circ}$ ).

(iv) The results show that the maximum value of the coupling factors is obtained for the (100) wafer.

Table 1.

According to Table 1 and Fig. 3, we observe that LFE increases the potential for eliminated unwanted modes and for driving certain modes of vibration. The greatest coupling factor is achievable for $b$ and $c$ modes with LFE by an appropriate selection of the angle of the electric field $\psi$ in (100) wafer. The same maximum value is reached for $b$ mode with TFE in (110) plane [25]. But as explained previously, in order to separate the biological media to the electronic of excitation, LFE has many advantages over TFE in the field of biosensors.

To conclude this part, we retain the (100) plane for the wafer orientation and an alignment of the electric field along $\langle 110\rangle$. Then a pure quasi shear mode is excited in the membrane. A rapid calculation of the coupling factor shift with the angle of alignment $\psi$ around $<100>$ shows a negligible change in $k$ (less than $1 \%$ in $\frac{\Delta k}{k}$ for $\Delta \psi$ less than $2^{\circ}$ ). So, the accuracy on the electrodes alignment is not a strong constraint in fabrication.

The resonance frequency $f_{R}$ of the membrane can be computed using equation (7). This relation leads to a decrease of $f_{R}$ with the thickness $t$ of the membrane which is shown in Fig. 4 in the case of fundamental mode $(n=1)$. It is important to take account of manufacturing and electronic measurement constraints of the device for designing the resonant structure. Also, since we can control the membrane thickness with an accuracy of $\pm 1 \mu \mathrm{m}$ and as we wish to obtain frequencies in the range of a few $\mathrm{MHz}$, this leads to a thickness $t$ of few tens of microns. We choose a thickness $t=50 \pm 1 \mu \mathrm{m}$, the frequency of the membrane will therefore be $f_{R}=33.53 \pm 0.65 \mathrm{MHz}$ for the fundamental mode and $f_{R 3}=100.23 \pm 2.01 \mathrm{MHz}$ for the partial rank 3 .

Fig. 4.

A Butterworth Van Dyke equivalent circuit (Fig. 5A) is used to describe the electrical and acoustical behaviour of our resonator. The circuit is composed of two parallel arms: (i) a static branch with the capacitance $\mathrm{C}_{0}$ which corresponds to the electrical behaviour of the device. 
(ii) a motional branch composed of the three serial elements $L_{m}, C_{m}$ and $R_{m}$ which represents the acoustic properties of the crystal plate. Each of the lumped elements considered in the circuit is defined below (equation (8)), according to the device geometry and the GaAs crystal constants. The relations are established in the case of (100) membrane and $\langle 110\rangle$ excited electric field.

$$
\begin{aligned}
& C_{0}=\frac{\varepsilon_{11} t d_{e}}{g} \\
& C_{m}=\frac{8 e_{14}{ }^{2} t d_{e}}{\pi^{2} C_{44}} \\
& L_{m}=\frac{g C_{44}}{32 e_{14}{ }^{2} t d_{e} f_{R}{ }^{2}} \\
& R_{m}=\frac{\pi^{2} \eta g C_{44}}{8 e_{14}{ }^{2} t w\left(C_{44}+\frac{e_{14}{ }^{2}}{\varepsilon_{11}}\right)}
\end{aligned}
$$

where $d_{e}, g$ and $\eta$ are respectively the electrode diameter, the gap width between electrodes and the attenuation factor in the crystal.

We firstly evaluated the static capacitance $\mathrm{C}_{0}$ (Fig. 5B) as a function of the distance between the two electrodes. The calculation of $\mathrm{C}_{0}$ was conducted for a gap in the range [0.1 $\mathrm{mm}, 1.2 \mathrm{~mm}]$. As expected, the static capacitance $\mathrm{C}_{0}$ decreases when the electrode gap increases.

The admittance magnitude of the equivalent circuit versus gap curve (not plotted here) shows the same evolution which is expected because far from resonant frequency, the equivalent circuit can be approximated by $\mathrm{C}_{0}$ (static capacitance arm on Fig. 5A). The selected value of the electrode gap will be determined by FEM analysis and the discussion will be given in the following section.

\section{Fig. 5.}

Fig. 6 illustrates the resonator behaviour around the resonance frequency (Fig. 6A). At the resonance frequency, $\mathrm{L}_{\mathrm{m}}$ (mass dependent) and $\mathrm{C}_{\mathrm{m}}$ (inversely proportional to the stiffness) reactances cancel, leaving only $\mathrm{R}_{\mathrm{m}}$ representing the dissipatives losses in the crystal. The height and the width of the resonance frequency peak that characterized the quality factor and the sensibility of the system are strongly dependent to the attenuation factor $\eta$. This factor, which depends on several parameters such as the GaAs viscosity, the interface between electrodes and surface membrane, the boundaries conditions, the surface roughness of the membrane, is difficult to evaluate and a value of $1.10^{-2}$ was retained to perform the curve in Fig. 6. The evolution of the quality factor Q (width of the resonance peak, Fig. 6B) and the admittance (height of the resonant peak, Fig. 6C) at the resonance frequency were performed for an attenuation factor $\eta$ between $1.10^{-2}$ and $1.10^{-1}$.

Fig. 6. 
The sensitivity of the mass sensor is shown in Fig. 7. We observe that the sensor could be able to detect a mass variation $\Delta \mathrm{m}$ of few picogram on its surface. As the relative variation of the resonant frequency can be detected until $10 \mathrm{~Hz}$, we conclude that the sensor can be able to detect a mass variation of 1 picogram on the surface. This performance gives the sensor a high competitiveness.

Fig. 7.

\subsection{FEM analysis}

To finalize the design of the structure, the size of electrodes and the gap between the electrodes must be defined. This study was conducted using the finite element software COMSOL ${ }^{\circledR}$.

FEM simulations are performed for membranes having on one hand the geometry characterized by vertical walls and on the other hand average values for length and width as evaluated from microfabrication. Due to the large membrane area, we can neglect the influence of the shapes (built-in on the sides of the membrane and inclined edges) on the results. The FEM analysis takes into account the anisotropy of the GaAs crystal. Active stress components and displacements are studied across the membrane area to verify the type of wave generated by the electrodes configuration. As expected, thickness shear waves propagating in the membrane are found. Table 2 gives the resonance frequencies (fundamental mode and partial rank 3) as computed from the analytical model and as evaluated by the simulator COMSOL ${ }^{\circledR}$. Values of the resonance frequency as collected using FEM simulation in Table 2 are close to theoretical values. There is a maximum discrepancy of $0.3 \%$.

Table 2.

Fig. 8.

To evaluate the gap between the electrodes, we perform calculations of the displacement versus the gap $g$. Fig. 8 shows the results of this study. We observe a decrease of the displacement with $g$. Two criteria need to be met in order to choose the gap value:

(i) a large area of vibration

(ii) a high value of displacement of the active surface.

In order to maintain a proper movement through a membrane of $2 \times 3 \mathrm{~mm}^{2}$ we choose a gap value of $g=0.8 \mathrm{~mm}$.

Based on the values obtained with numerical and analytical simulations, we present in the next section the fabrication process and some realizations step by step.

\section{Microfabrication}

\subsection{Fabrication process}

Our experimental work concerns the fabrication of the resonant structure using photolithography and micromachining processes. The geometry of the structure is shown in Fig. 1. Both faces of a commercial (100) wafer were mechanically polished and the initial thickness is about $400 \mu \mathrm{m}$. As summarized in Fig. 9 three steps are necessary to fabricate the resonant structure: 
(i) Electrode deposition: a bilayer (gold and grip layer) is deposited by evaporation and patterned by a photolithographic process to obtain the desired shape of electrodes.

(ii) Wafer thinning: the desired performances of the device require a precise control of the membrane thickness. The thinning step leads to a decrease of the etching depth during the membrane micromachining. This results in a better control of the membrane thickness. This step requires the following features: flatness, smooth surface without porosities (no bubble during the thinning). A fast etching rate to minimize the etching time is possible since an error on the thickness after thinning is tolerated.

(iii) Membrane micromachining: this is the most important step of the process. The etching rate must be perfectly controlled to minimize the uncertainty on the membrane thickness. No shaping defaults or disorientations are allowed. The roughness of the active surface plays an important role because, on one hand, it influences the quality factor of the resonator and, on the other hand, it can improve the grafting yield of molecules on the functionalized surface. A specific study must be done to optimize the surface texture.

Fig. 9.

A characterisation of the surface states and sizes must be performed at different steps of the process. Depth measurements were realized with a Dektak profilometer (depth $<50 \mu \mathrm{m}$ ) or an Alphastep (depth $>50 \mu \mathrm{m}$ ). The surface topography was imaged by AFM (Veeco multimode AFM) in air using contact mode. Roughness parameters were quantified from the AFM data and the profilometer profile with a home-made software.

\subsection{Wet etching surfaces}

As already seen, to obtain a low cost device, the two last steps of fabrication were realized by wet etching. The etching solutions are composed of an oxidant, an acidic or a basic solution and sometimes a diluent solution. By a variation in composition and concentration of the etching bath, we are able to obtain a large panel of etching rates and patterned surfaces, as already published [26]. The fabrication requirements for the wafer thinning and the membrane microfabrication are not the same.

For the substrate thinning, the main specification concerns the quality of the surface state. Two kinds of reactions lead to smooth surfaces: the fast ones [27-29] and the slow ones [30]. Among the fast reactions, some can be ignored for safety reasons [27-29] and some others because they induce surface alterations [31]. The first eight solutions mentioned in table 3 were tested.

The micromachining of the membrane leads to a 3D shape. The control of the membrane thickness and the lateral underetching is of main importance for the device behaviour. Many experimental studies [10, 32-35] show the panel of 3D shapes which can be realized by changing the anisotropic properties of the baths. The most commonly etching solutions used are composed of sulphuric or phosphoric acid. Previous studies [33-35] show that $\mathrm{H}_{3} \mathrm{PO}_{4}$ : 9 $\mathrm{H}_{2} \mathrm{O}_{2}: \mathrm{H}_{2} \mathrm{O}$ and $\mathrm{H}_{2} \mathrm{SO}_{4}: 8 \mathrm{H}_{2} \mathrm{O}_{2}: \mathrm{H}_{2} \mathrm{O}$ baths (etching solutions 9 and 10 in Table 3) induce smooth sidewalls for the vibrating area due to very low etching rates of the $\{111\}_{\text {Ga }}$ planes.

To choose the etching baths, two characteristics have to be satisfied:

(i) the etching rates and the anisotropy of the etchants

(ii) the surface roughness 


\subsubsection{Etching rates}

To evaluate the anisotropy of etchants, the etchings rates were measured at room temperature $\left(\mathrm{T}=22^{\circ} \mathrm{C}\right.$ ) called $\mathrm{T}_{22}$ on several plane orientations: (100), (110) and (111) planes. The results for (100) substrate orientation are given in Table 3. During the process, in order to ensure a uniform etching of the surface, we have to take care of the sample position (gradient in concentration must be avoided) and the renewal of the solution at each point of the surface. Unlike the membrane which must be fabricated by using an anisotropic bath, the thinning can be performed either in an anisotropic or an isotropic bath.

Table 3.

In Table 3, we observe the influence of stirring on the etch rate in the case of $\mathrm{H}_{2} \mathrm{SO}_{4}$ based solution. Stirring must be well controlled to improve the renewal of the solution at the surface but we have to take care of changes in the reaction mechanism if stirring becomes too fast. Due to a bad stability over time, sulfuric acid based solutions cannot be retained.

According to the etching rate criteria, the results reveal that $\mathrm{HNO}_{3}$ based solutions $(6,7$ and 8$)$ and the phosphoric acid based bath (4) are more accurate for thinning and the phosphoric acid based bath (9) is better for membrane micromachining.

It is well known that temperature has a marked influence on the etch rates. Consequently, in the case of membrane micromachining, it is particularly important to control the bath temperature. The evolution of the etch rate with low temperature was investigated for the phosphoric acid solution (bath $\mathrm{n}^{\circ}$ ). Results are given in Fig. 10.

Fig. 10.

As expected, Fig. 10 showing the evolution of the etch rate with $\mathrm{T}\left(-10^{\circ} \mathrm{C}<\mathrm{T}<15^{\circ} \mathrm{C}\right)$ verifies the Arrhenius law (dotted line), i.e. the etching rate follows an exponential function of T. A low temperature would be used to improve the control of membrane thickness at the end of the process.

\subsubsection{Surface roughness}

Several parameters influence the surface patterning and also the roughness parameters of the surface:

(i) composition and concentration of etchants

(ii) temperature $\mathrm{T}$

(iii) stirring

Fig. 11.

The AFM images (Fig. 11) illustrate the change in topography induced by a change in T, composition and concentration of bath. Fig. 11A and 11B give evidence of the stirring effect on the surface texture in the case of the $1 \mathrm{H}_{2} \mathrm{SO}_{4}: 2 \mathrm{HCl}: 3 \mathrm{~K}_{2} \mathrm{Cr}_{2} \mathrm{O}_{7}$ solution. Stirring increases the size of the motifs. The influence of the composition of etchants on the surface texture is illustrated in fig. 11C, 11D and 11E. The dissolution figures are completely different, bigger and more marked in Fig. 11D. The observation in fig. $11 \mathrm{~F}$ and fig. $11 \mathrm{G}$ reveals that the surface state disturbed by the presence of bubbles during etching (Fig.11G), can be improved by changing the operating temperature (Fig.11F). The decrease of $\mathrm{T}$ from ambient to $10^{\circ} \mathrm{C}$ causes the disappearance of the bubbles present during the chemical etching. 
Fig. $11 \mathrm{G}$ and $11 \mathrm{H}$ show the influence of diluent solutions on the surface texture. Here again, the diluent solution contributes to the disappearance of bubbles and leads to a polished surface.

To complete the discussion on AFM images, roughness parameters were calculated on several $10 \mu \mathrm{m} \times 10 \mu \mathrm{m}$ images with a resolution of 512 x 512 pixels. Ra and Rms values are given in table 4 for some selected baths with different operating conditions.

\section{Table 4.}

Again, these results show the influence of temperature and stirring on the surface properties and confirm the choice of $7 \mathrm{H}_{3} \mathrm{PO}_{4}: 5 \mathrm{H}_{2} \mathrm{O}_{2}: 8 \mathrm{H}_{2} \mathrm{O}$ solution as thinning etchant. This solution which exhibits the lowest roughness parameters provides a highly polished surface.

The roughness parameters of the surface etched in the phosphoric acid solution $1 \mathrm{H}_{3} \mathrm{PO}_{4}: 9$ $\mathrm{H}_{2} \mathrm{O}_{2}: 1 \mathrm{H}_{2} \mathrm{O}$ are close to $3 \mathrm{~nm}$. The roughness of the active membrane surface due to the presence of dissolution figures may be an advantage to increase the number of biomolecules that need to be grafted. Moreover, the surface roughness should not lead to a decrease in the quality factor of the resonator. A compromise between these two criteria must be found to optimize the sensitivity of the biosensor.

\subsection{Microfabrication of the membrane}

Our final aim concerns the fabrication of the membrane obtained through photolithography and micromachining processes. Four steps are necessary to fabricate the membrane as shown on the flow chart given in Fig. 12.

Fig. 12.

The four successive steps consist of:

(i) A cleaning process that has been established to remove mineral and organic impurities present on the samples' surface.

(ii) The thinning of one face of the substrate in the $7 \mathrm{H}_{3} \mathrm{PO}_{4}: 5 \mathrm{H}_{2} \mathrm{O}_{2}: 8 \mathrm{H}_{2} \mathrm{O}$ solution whereas the other face is protected by a photoresist. Although two times slower than a double side etching, this method allows the electrodes coating before all the micromachining steps and increases the control of the etched surface flatness by a proper positioning of sample.

(iii) The thickness control. Despite the reproducibility of the chemical etching process, a long etching duration, some environmental parameters make it complicated to control the membrane thickness. A thickness control was defined on the structure to overcome this difficulty. It consists in the etching of a small hole whose depth, perfectly controlled, was equal to the final desired thickness membrane. It is possible to reach a high accuracy in depth with a low temperature etching $\left(\mathrm{T}=-10^{\circ} \mathrm{C}\right.$ in the $1 \mathrm{H}_{3} \mathrm{PO}_{4}: 9 \mathrm{H}_{2} \mathrm{O}_{2}: 1 \mathrm{H}_{2} \mathrm{O}$ solution) since only a small volume of GaAs is removed.

(iv) The micromachining of the membrane in the $1 \mathrm{H}_{3} \mathrm{PO}_{4}: 9 \mathrm{H}_{2} \mathrm{O}_{2}: 1 \mathrm{H}_{2} \mathrm{O}$ solution. During this step, the hole was in contact with the etchant and consequently the etching rate is the same for the membrane and for the hole which are on the same face of the substrate. The opposite face is covered by a resin layer to avoid etching and to protect electrodes. We stop the dissolution 
process when the hole is leading. Thus, the hole fabrication decreases the number of membrane thickness measurements and limits the breaking risks.

Fig. 13.

Fig. 13A exhibits an image of the membrane whose thickness was supposed to be equal to 50 $\mu \mathrm{m}$. The shape and lateral size of the structure are in adequation with the predicted values. The underetching and the angle of limiting facets inclined with respect to the reference plane are characterized. The main difficulty remains in the uniformity of the membrane thickness. Indeed, even if we control the thickness membrane using the hole, deviations occur on the surface of the membrane $(t=50 \mu \mathrm{m} \pm 1 \mu \mathrm{m})$. Defects in material and an inhomogeneous renewal of the etchant at the surface due to a poor rate of stirring could be the causes of the deviation of membrane thickness. Fig. 13B and 13C give etching profiles in two perpendicular cross sections of the (100) etched wafer. These images of (110) and (1 $\overline{1} 0)$ sections don't exhibit the same etching profile. Indeed, in Fig. 13B, we distinguish the development of an "inward" shoulder correlated with the $\{111\}_{\mathrm{Ga}}$ maximum of the dissolution slowness. This plane corresponds to a theoretical angle of $125.3^{\circ}$ with the reference plane (100). The experimental mean value of angle is $\beta=118^{\circ}$ which is close accord with the theoretical one (the deviation is less than 6\%) and in agreement with the values given in ref $[14,34]$ in the case of an acidic peroxide solution of etching. In fig. 13C, it appears that the etching gives rise to a dissolution profile composed of two successive elements. The two corresponding mean values of angle are $\alpha_{1}=52^{\circ}$ and $\alpha_{2}=30^{\circ}$ with respect to the reference plane. The angle $\alpha_{1}$ clearly corresponds to the $\{111\}_{\text {Ga }}$ plane (the deviation is less than $5 \%$ ). The angle $\alpha_{2}$ corresponds to the inclination of a facet situated between a $\{112\}$ and a $\{113\}$ plane. These facets are already observed by T. Takabe et al [28]. Fig. 13B gives also evidence of curved profile near the embedding of the membrane which can be explained by the relatively low anisotropy of the dissolution process. A specific consideration must also be focused on the surface texture. Fig. 14 shows profilometry traces performed on the etched surface of the membrane (working distance equal to $500 \mu \mathrm{m}$ ).

Fig. 14.

The amplitudes measured on the surface profile vary from -0.1 to $0.1 \mu \mathrm{m}$. The wave profile (Fig. 14B) shows that the size of the figures generated on the etched surface are about $300 \mu \mathrm{m}$ large. These features are then relatively flat and will not induce a decrease of the resonator performances. The surface roughness parameters were obtained with a cut off equal to $80 \mu \mathrm{m}$. The mean roughness parameters are $\mathrm{Ra}=10.5 \mathrm{~nm}$ and $\mathrm{Rq}=17.9 \mathrm{~nm}$. These results are slightly different from the previous tests related in section 3.2 but the difference is due to the characterization method and the sampling resolution [36].

\section{Conclusion}

An analytical model for the piezoelectric lateral field excitation of GaAs membrane is proposed. Theoretical expressions of the resonance frequency are derived for thickness shear modes. The possibility with commercial cuts to design structures vibrating in pure mode is explored. For the selected cut and electric field alignments the resonance frequency, the equivalent circuit admittance, the $\mathrm{Q}$ value and the mass sensitivity are evaluated. A complementary FEM analysis allowed dimensioning the device. We have determined the design of the structure that will provide a sensor where the electronics part is separated from 
the liquid medium. The wet etching is the process retained for the microfabrication of the structure. The fabrication process is established and the micromachining is in progress. The micromachining process leads to a membrane with low surface roughness which will not affect the quality factor of the resonant membrane because the features appeared on the surface are very small compared to the wavelength of the resonant structure. Nevertheless, some experimental tests are still in progress to reduce the amplitude of the wave surface profile. The success in molecule grafting associated with the high performances reached by our GaAs resonant device are good assets in view of the realization of a new kind of biosensors. Future experimental tests will allow us to reach the detection limits of the sensors and verify the expected sensitivity of $0.1 \mathrm{pg} / \mathrm{Hz}$. 


\section{References}

1. L. Nicu, M. Guirardel, F. Chambosse, P. Rougerie, S. Hinh, E. Trevisiol, J.M. François, J.P. Majoral, A.M. Caminade, E. Cattan, C. Bergaud, Sens. Actuators B. 110, 125 (2005)

2. D. Maraldo, R. Mutharasan, Sens. Actuators B. 143, 731 (2010)

3. Y. Hu, A. French, J.K. Radecsky, M. Pereira da Cunha, P. Millard, J.F. Vetelino, IEEE Trans. Ultrason. Ferroelectr. Freq. Control. 51 n $^{\circ} 11,1373$ (2004)

4. S.J. Martin, G.C. Frye, K.O. Wessendorf, Sens. Actuators A. 44, 209 (1994)

5. B.P. Stehrer, H. Gruber, R. Schwödiauer, I.M. Graz, S. Bauer, in Proceedings of the Eurosensors XXIII Conference, 2009, Procedia Chemistry 1, p.1507

6. J. Zhang, S.O'Shea, Sens. Actuators B. 94, 65 (2003)

7. J. Söderkvist, Sens. Actuators A. 43, 65 (1994)

8. C.R. Tellier, T. Leblois, IEEE Trans. on Ultrasonics, Ferroelectrics, and Frequency Control, $47 \mathrm{n}^{\circ} 5,1204$ (2000)

9. T. Leblois, C.R. Tellier, Sens. Actuators A. 99, 256 (2002)

10. C.R. Tellier, G. Huve, T. Leblois, Sens. Actuators A. 127, 179 (2006)

11. F. Fricke, J. Appl. Phys. 70, 1914 (1991)

12. H. Ukita, Y. Uenishi, H. Tanaka, Science 260, 786 (1993)

13. K. Hjort, J. Söderkvist, J.A. Schweitz, J. Micromech. Microeng. 4, 1 (1994)

14. S. Ida, K. Ito, J. Electrochem. Soc.: Solid State Sci. 118, 768 (1971)

15. Z.L. Zhang, N.C. MacDonald, J. Microelectromechanical Syst. 2, 66 (1993)

16. K. Hjort, J. Micromech. Microeng. 6, 370 (1996)

17. J. Miao, H.L. Hartnagel, D. Rück, K. Fricke, Sens. Actuators A. 46, 30 (1995)

18. J. Miao, H. Hartnagel, Sens. Actuators A. 114, 505 (2004)

19. D.M. Wieliczka, X. Ding, J.J. Dubowski, J. Vac. Sci. Technol. A. 24(5), 1756 (2006)

20. H.A. Budz, R.R. Lapierre, J. Vac. Sci. Technol. A. 26(6), 1425 (2008)

21. A. Ballato, in Proceedings of IEEE International Frequency Control Symposium, Kansas City, MO, 2000, p. 340

22. P.C.Y. Lee, in Proceedings of IEEE Ultrasonics Symposium, Chicago (USA), 1988, p. 407

23. C.D. Corso, A. Dickherber, W. D. Hunt, J. Appl. Phys. 101, ARTN 054514 (2007)

24. T.R. Meeker, IEEE Standard on Piezoelectricity, ANSI/IEEE Std 176, (1987)

25. K. Hjort, G. Schweeger, A. Dehe, K. Fricke and H.L. Hartnagel, Appl. Phys. Lett. 66, 326 (1995)

26. A. Bienaime, C. Elie-Caille, T. Leblois, J. Nanosci. Nanotechnol., accepted (2011)

27. S. Adachi, D. Kikuchi, J. Electrochem. Soc. 147 nº12, 4618 (2000)

28. T. Takebe, T. Yamamoto, M. Fujii, K. Kobayashi, J. Electrochem. Soc. 140 n $^{\circ} 4,1169$ (1993)

29. S.W. Wilson, R.W. Armstrong, M. Dagenais, W.T. Beard, C.E.C. Wood, J. Mater. Sci. Electron. 8, 109 (1997)

30. C. Bryce, D. Berk, Ind. Eng. Chem. Res. 35, 4464 (1996)

31. B. Tuck, J. Mat. Sci. 10, 321 (1975)

32. S. Adachi, K. Oe, J. Electrochem. Soc. 130 n$^{\circ} 12$, 2427 (1983)

33. D.N. MacFayden, J. Electrochem. Soc.: Solid State Sci. 130, 1934 (1983)

34. D. W. Shaw, J. Electrochem. Soc.: Solid State Sci. 128, 874 (1981)

35. C.R. Tellier, T.G. Leblois, Sens. Actuators A. 132, 224 (2006)

36. C.Y. Poon, B. Bhushan, Wear 190, 76 (1995) 


\section{Captions to Figures}

Fig. 1. Design of the resonant GaAs structure

Fig. 2. Definition of primed axes: wafer orientation (A), membrane and electric field orientation $(\mathrm{B}, \mathrm{C})$

Fig. 3. Electromechanical coupling coefficients $k$ as a function of electric field angle $(\psi)$ for the three cuts: A (100), B (110), C (111) and D (211) plates. The three modes of vibration are given in solid lines (quasi-longitudinal mode), dashed lines (fast quasi-shear mode) and dotted lines (slow quasi-shear mode)

Fig. 4. Variation of the resonance frequency $f_{\mathrm{R}}$ with the thickness of the membrane. A resonance frequency $f_{\mathrm{R}}=33.53 \pm 0.65 \mathrm{MHz}$ was computed for a thickness of $t=50 \pm 1 \mu \mathrm{m}$.

Fig. 5. Butterworth Van Dyke equivalent circuit (A) and static capacitance $C_{0}$ versus electrode spacing (B).

Fig. 6. Admittance response around the resonance frequency $f_{\mathrm{R}}=33.5295 \mathrm{MHz}(\mathrm{A})$; evolution of the quality factor (B) and the admittance (C) with the attenuation factor $\eta$.

Fig. 7. Shift of resonance frequency $\left(\Delta f_{R}\right)$ induced by a small variation of mass $\Delta \mathrm{m}$ on the sensitive surface.

Fig. 8. Particles displacement versus the gap between electrodes for a membrane thickness $t=$ $50 \mu \mathrm{m}$

Fig. 9. Fabrication steps of the resonant GaAs structure

Fig. 10. Evolution of etching rates of (100) GaAs plane in the $\mathrm{H}_{3} \mathrm{PO}_{4}: 9 \mathrm{H}_{2} \mathrm{O}_{2}: \mathrm{H}_{2} \mathrm{O}$ solution with the temperature $\mathrm{T}$

Fig. 11. AFM images $(10 \mu \mathrm{m} \times 10 \mu \mathrm{m})$ of (100) etched surfaces in different operating conditions: (A) $1 \mathrm{H}_{2} \mathrm{SO}_{4}: 2 \mathrm{HCl}: 3 \mathrm{~K}_{2} \mathrm{Cr}_{2} \mathrm{O}_{7}$ solution at $\mathrm{T}_{22}, \mathrm{Z}_{\text {range }}=50 \mathrm{~nm}$; (B) $1 \mathrm{H}_{2} \mathrm{SO}_{4}: 2$ $\mathrm{HCl}: 3 \mathrm{~K}_{2} \mathrm{Cr}_{2} \mathrm{O}_{7}$ solution at $\mathrm{T}_{22}$ with stirring, $\mathrm{Z}_{\text {range }}=75 \mathrm{~nm}$; (C) $1 \mathrm{H}_{3} \mathrm{PO}_{4}: 1 \mathrm{H}_{2} \mathrm{O}_{2}: 1 \mathrm{H}_{2} \mathrm{O}$ at $\mathrm{T}_{22}, \mathrm{Z}_{\text {range }}=30 \mathrm{~nm}$; (D) $1 \mathrm{H}_{3} \mathrm{PO}_{4}: 9 \mathrm{H}_{2} \mathrm{O}_{2}: 1 \mathrm{H}_{2} \mathrm{O}$ at $\mathrm{T}_{22}, \mathrm{Z}_{\text {range }}=50 \mathrm{~nm}$; (E) $7 \mathrm{H}_{3} \mathrm{PO}_{4}: 5$ $\mathrm{H}_{2} \mathrm{O}_{2}: 8 \mathrm{H}_{2} \mathrm{O}$ at $\mathrm{T}_{22}, \mathrm{Z}_{\text {range }}=20 \mathrm{~nm}$; (F) $1 \mathrm{HNO}_{3}: 1 \mathrm{H}_{2} \mathrm{O}_{2}$ solution with $\mathrm{T}=10^{\circ} \mathrm{C}, \mathrm{z}_{\text {range }}=30$ $\mathrm{nm}$; (G) $1 \mathrm{HNO}_{3}: 1 \mathrm{H}_{2} \mathrm{O}_{2}$ solution at $\mathrm{T}_{22}, \mathrm{Z}_{\text {range }}=65 \mathrm{~nm} ;(\mathrm{H}) 1 \mathrm{HNO}_{3}: 1 \mathrm{H}_{2} \mathrm{O}_{2}: 1 \mathrm{H}_{2} \mathrm{O}$ solution at $\mathrm{T}_{22}, \mathrm{Z}_{\mathrm{range}}=30 \mathrm{~nm}$. Images in air and using the contact mode.

Fig. 12. Flow chart of the GaAs membrane fabrication

Fig. 13. Optical microscopic image of the etched (100) GaAs membrane (A) view from the top of the etched membrane; $(\mathrm{B}, \mathrm{C})$ view of etching profiles obtained by cleaving the wafer in orthogonal directions along the $(1 \overline{1} 0)$ and (110) cross sections respectively 
Fig. 14. Profilometry traces (working distance $=500 \mu \mathrm{m}$ ) of the membrane surface: $(\mathrm{A})$ total profile; (B) wave profile; (C) roughness profile (cut off $=80 \mu \mathrm{m}$ ) 


\section{Table Captions:}

Table 1. TFE and LFE coupling factors for the selected orientations of wafers.

Table 2. Values of the resonance frequencies (in $\mathrm{MHz}$ ) as computed from equation (7) and as evaluated from FEM simulation.

Table 3. Etching rates measured at a constant room temperature of $22^{\circ} \mathrm{C}\left(\mathrm{T}=\mathrm{T}_{22}\right)$.

Table 4. Roughness parameters of (100) etched GaAs surfaces in several conditions of temperature (room temperature of $22^{\circ} \mathrm{C}$ or $10^{\circ} \mathrm{C}$ ) and stirring. 


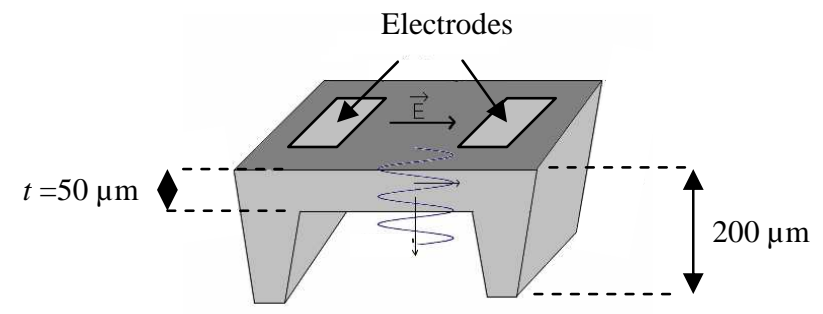

Fig. 1. Design of the resonant GaAs structure 
(A)

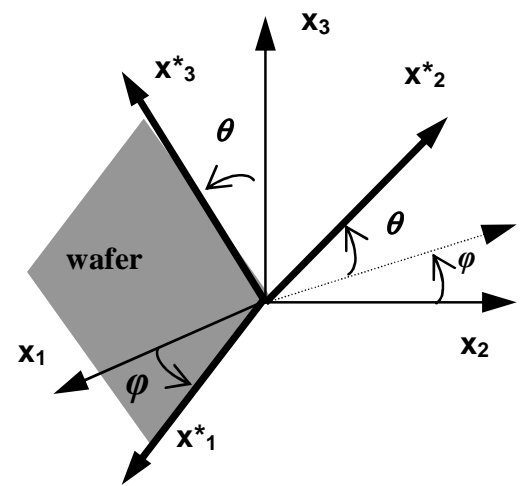

(B)

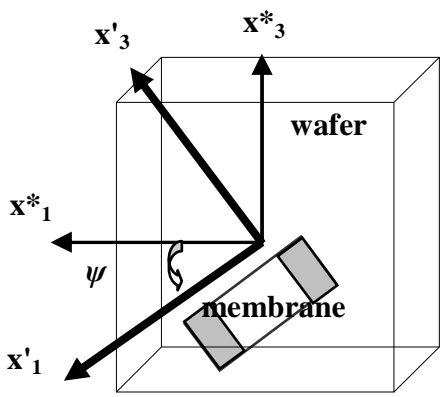

(C)

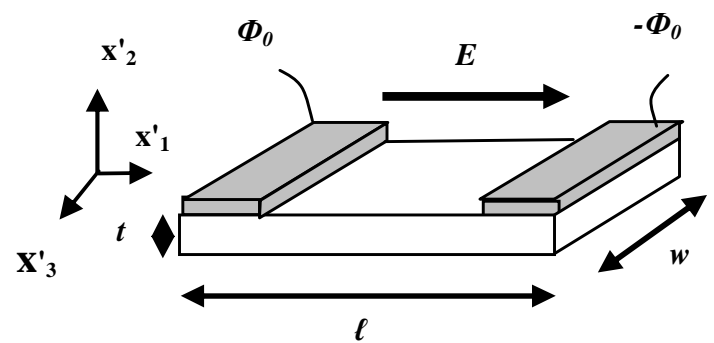

Fig. 2. Definition of primed axes: wafer orientation (A), membrane and electric field orientation (B, C) 

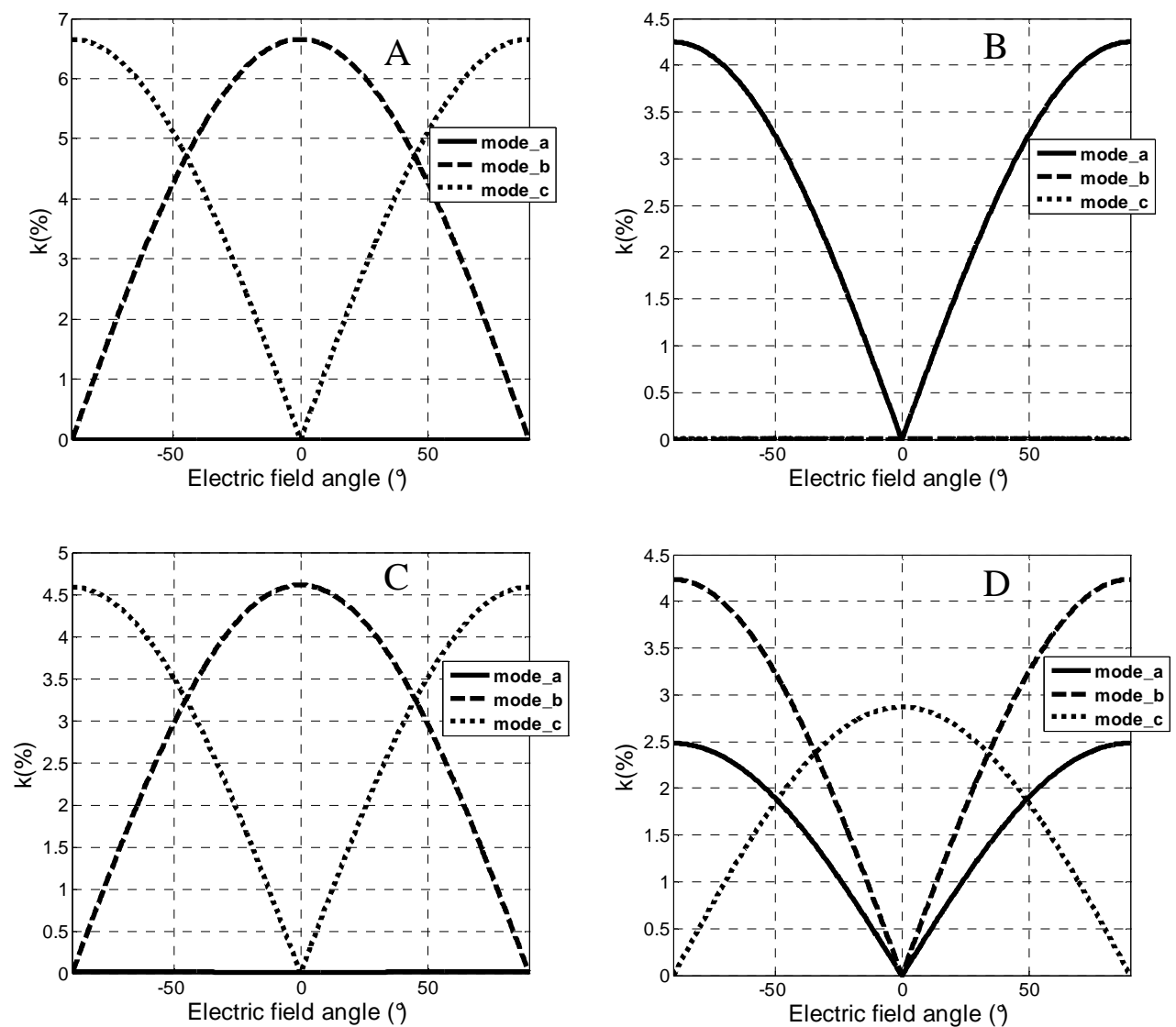

Fig. 3. Electromechanical coupling coefficients $k$ as a function of electric field angle ( $\psi$ ) for the three cuts: A (100), B (110), C (111) and D (211) plates. The three modes of vibration are given in solid lines (quasi-longitudinal mode), dashed lines (fast quasi-shear mode) and dotted lines (slow quasi-shear mode) 


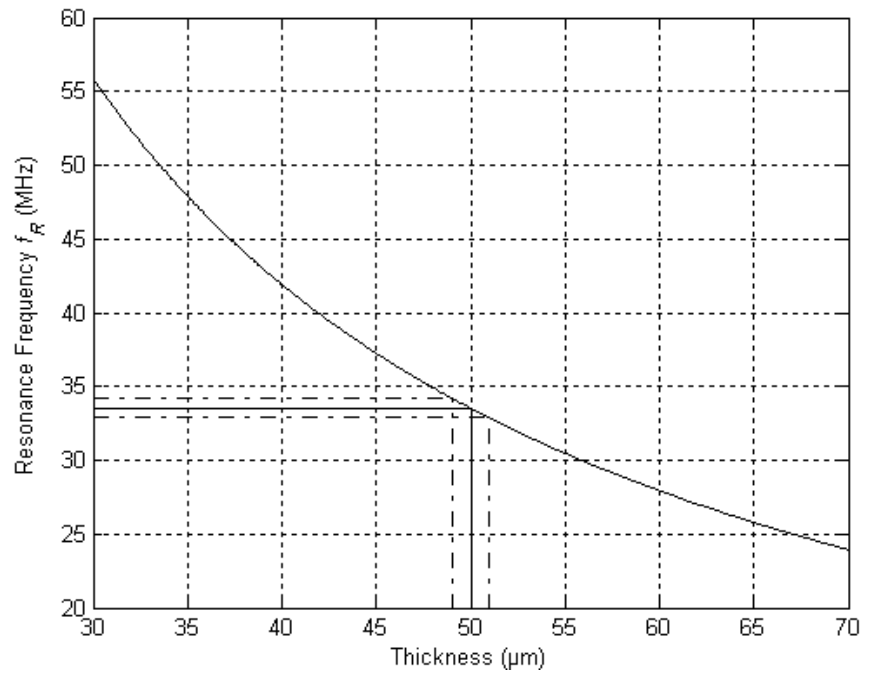

Fig. 4. Variation of the resonance frequency $f_{R}$ with the thickness of the membrane. A resonance frequency $f_{R}=33.53 \pm 0.65$ MHz was computed for a thickness of $t=50 \pm 1 \mu \mathrm{m}$. 

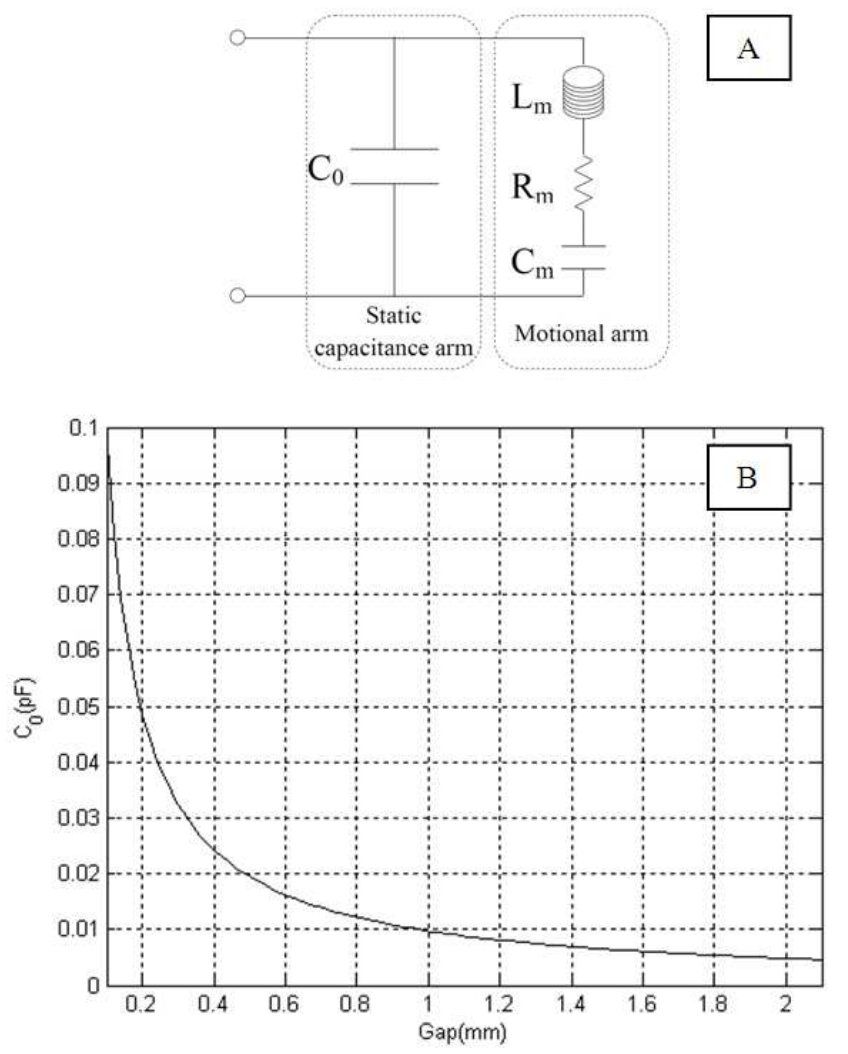

Fig. 5. Butterworth Van Dyke equivalent circuit (A) and static capacitance $C_{0}$ versus electrode spacing (B). 

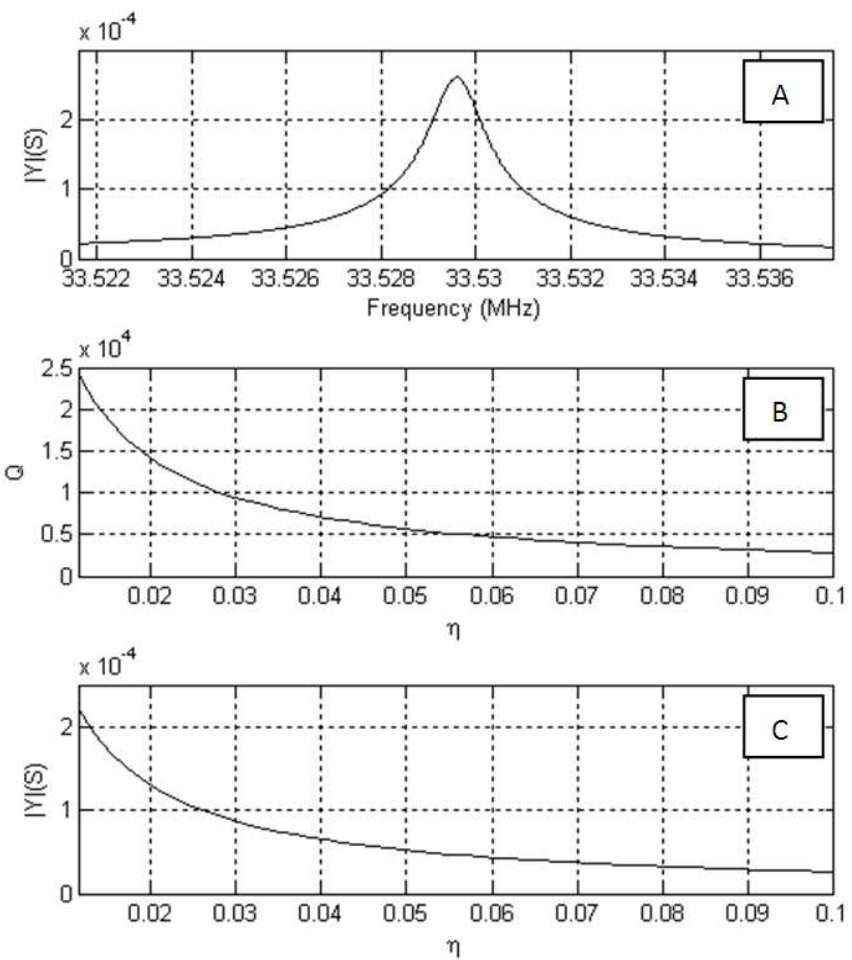

Fig. 6. Admittance response around the resonance frequency $f_{\mathrm{R}}=33.5296 \mathrm{MHz}$ (A); evolution of the quality factor (B) and the admittance $(\mathrm{C})$ with the attenuation factor $\eta$. 


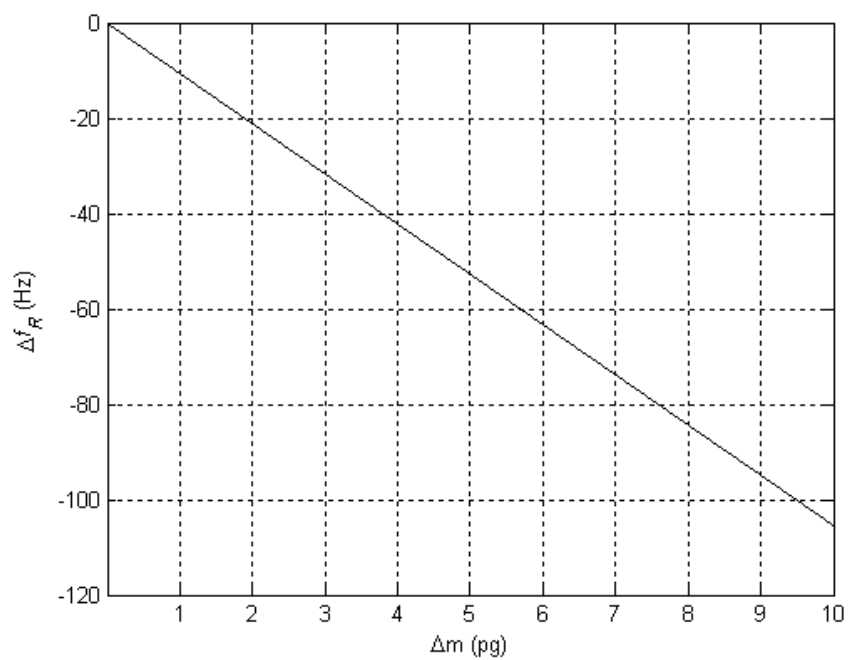

Fig. 7. Shift of resonance frequency $\left(\Delta f_{R}\right)$ induced by a small variation of mass $\Delta \mathrm{m}$ on the sensitive surface. 


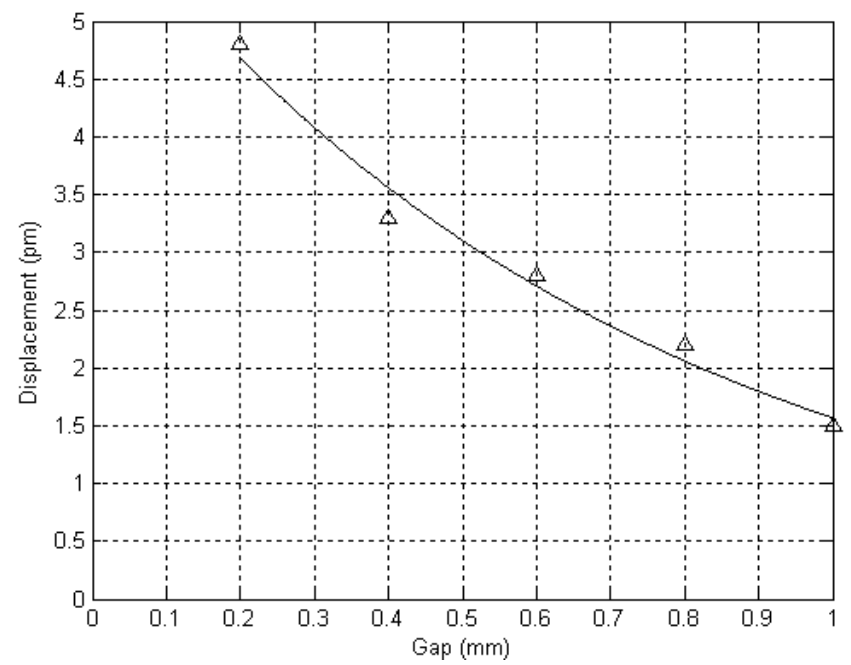

Fig. 8. Particles displacement versus the gap between electrodes for a membrane thickness $t=50 \mu \mathrm{m}$ 


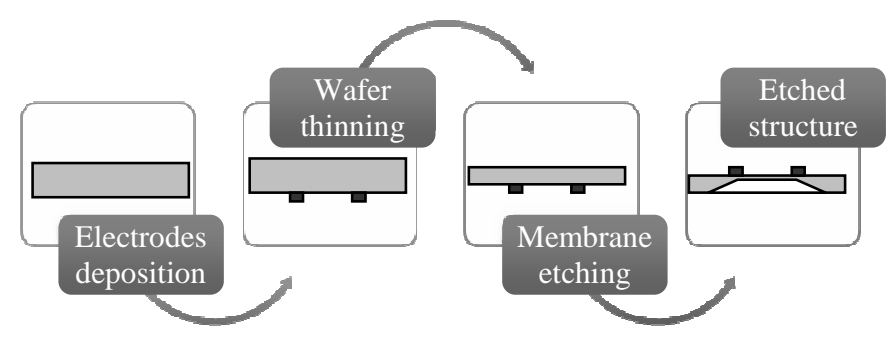

Fig. 9. Fabrication steps of the resonant GaAs structure 


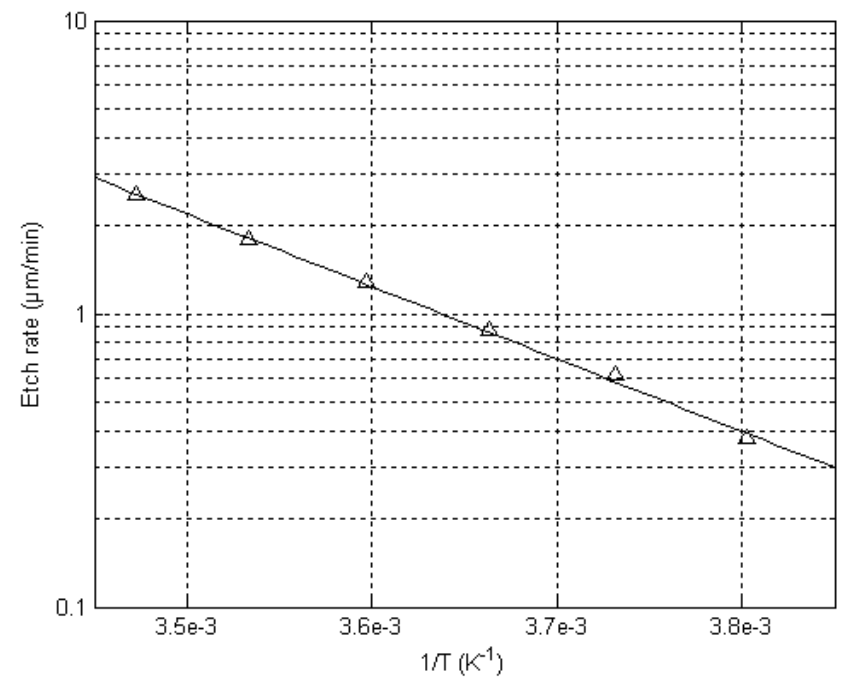

Fig. 10. Evolution of etching rates of a (100) GaAs plane in the $\mathrm{H}_{3} \mathrm{PO}_{4}: 9 \mathrm{H}_{2} \mathrm{O}_{2}: \mathrm{H}_{2} \mathrm{O}$ solution with the temperature $\mathrm{T}$ 

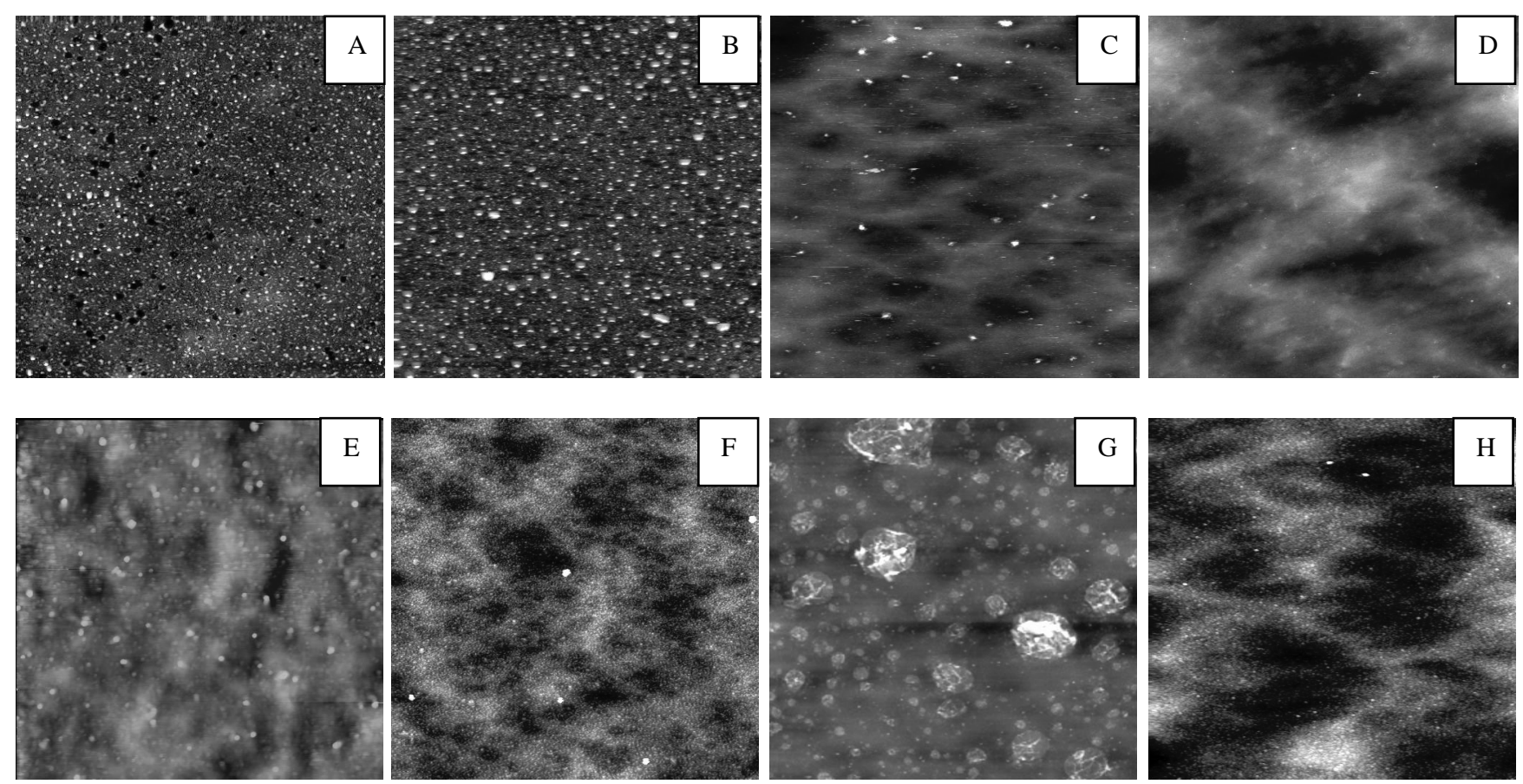

Fig 11 AFM images $(10 \mu \mathrm{m} \times 10 \mu \mathrm{m})$ of (100) etched surfaces in different operating conditions: (A) $1 \mathrm{H}_{2} \mathrm{SO}_{4}: 2 \mathrm{HCl}: 3$ $\mathrm{K}_{2} \mathrm{Cr}_{2} \mathrm{O}_{7}$ solution at $\mathrm{T}_{22}, \mathrm{z}_{\text {range }}=50 \mathrm{~nm}$; (B) $1 \mathrm{H}_{2} \mathrm{SO}_{4}: 2 \mathrm{HCl}: 3 \mathrm{~K}_{2} \mathrm{Cr}_{2} \mathrm{O}_{7}$ solution at $\mathrm{T}_{22}$ with stirring, $\mathrm{z}_{\text {range }}=75 \mathrm{~nm}$; (C) 1 $\mathrm{H}_{3} \mathrm{PO}_{4}: 1 \mathrm{H}_{2} \mathrm{O}_{2}: \quad 1 \mathrm{H}_{2} \mathrm{O}$ at $\mathrm{T}_{22}, \mathrm{Z}_{\text {range }}=30 \mathrm{~nm}$; (D) $1 \mathrm{H}_{3} \mathrm{PO}_{4}: 9 \mathrm{H}_{2} \mathrm{O}_{2}: 1 \mathrm{H}_{2} \mathrm{O}$ at $\mathrm{T}_{22}, \mathrm{z}_{\text {range }}=50 \mathrm{~nm}$; (E) $7 \mathrm{H}_{3} \mathrm{PO}_{4}: 5$ $\mathrm{H}_{2} \mathrm{O}_{2}: 8 \mathrm{H}_{2} \mathrm{O}$ at $\mathrm{T}_{22}, \mathrm{Z}_{\text {range }}=20 \mathrm{~nm} ;(\mathrm{F}) 1 \mathrm{HNO}_{3}: 1 \mathrm{H}_{2} \mathrm{O}_{2}$ solution with $\mathrm{T}=10^{\circ} \mathrm{C}, \mathrm{z}_{\text {range }}=30 \mathrm{~nm} ;(\mathrm{G}) 1 \mathrm{HNO}_{3}: 1 \mathrm{H}_{2} \mathrm{O}_{2}$ solution at $\mathrm{T}_{22}, \mathrm{Z}_{\text {range }}=65 \mathrm{~nm} ;(\mathrm{H}) 1 \mathrm{HNO}_{3}: 1 \mathrm{H}_{2} \mathrm{O}_{2}: 1 \mathrm{H}_{2} \mathrm{O}$ solution at $\mathrm{T}_{22}$, $\mathrm{Z}_{\text {range }}=30 \mathrm{~nm}$. Images in air using contact mode. 


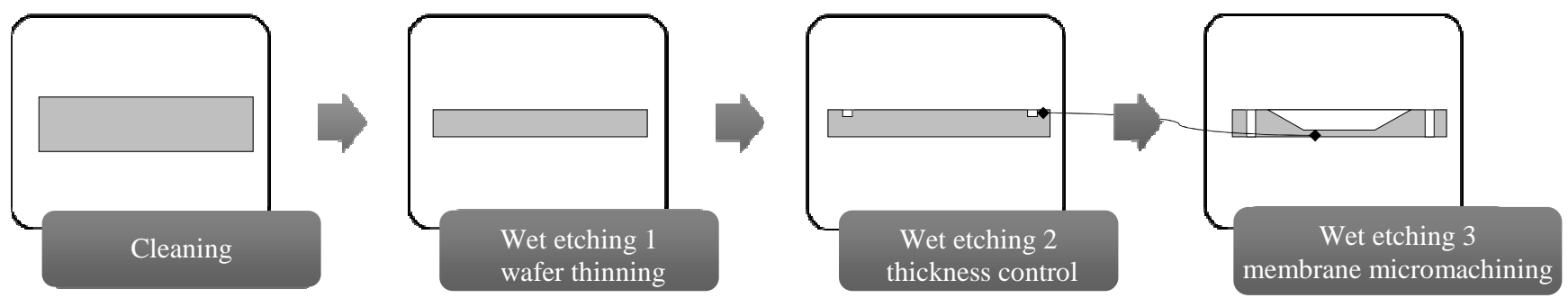

Fig. 12. Flow chart for the fabrication of the GaAs membrane 

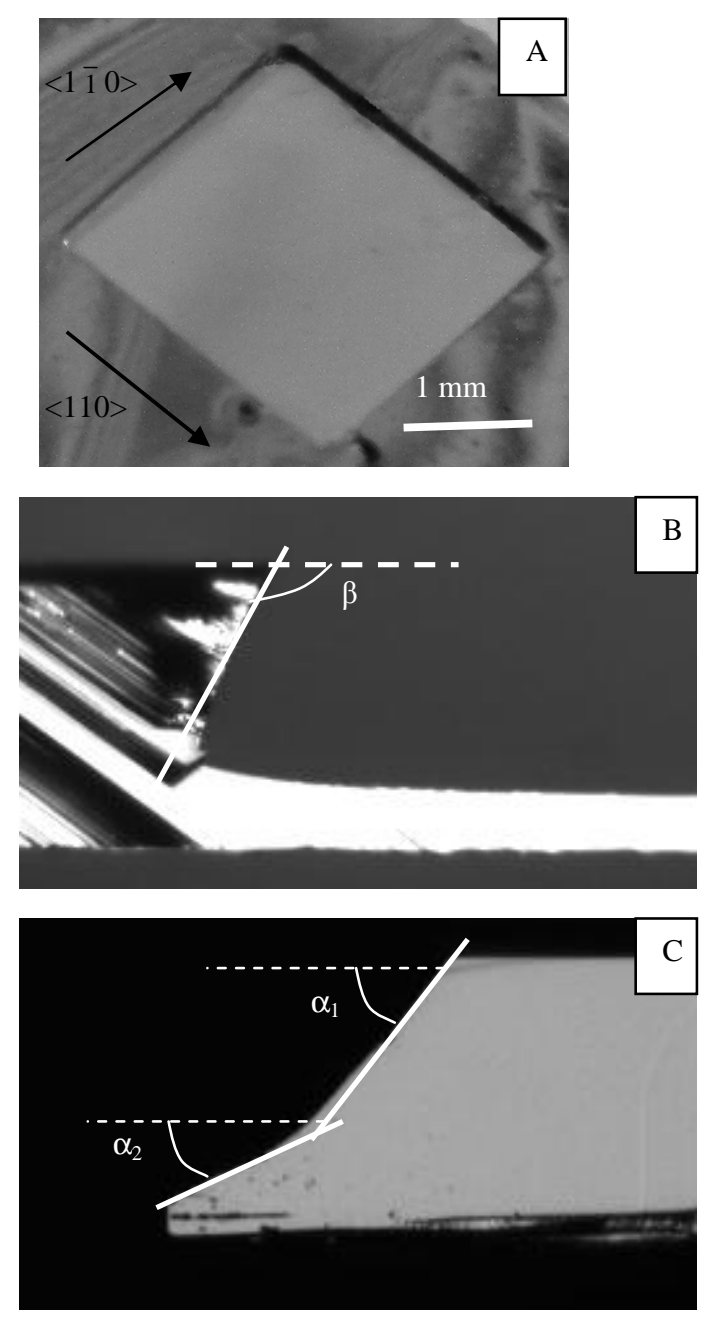

Fig. 13. Optical microscopic images of the etched (100) GaAs membrane: (A) View from the top of the etched membrane; $(B, C)$ Profile views of etching profiles obtained by cleaving the wafer in orthogonal directions along the (1 10$)$ and $(110)$ cross sections respectively 

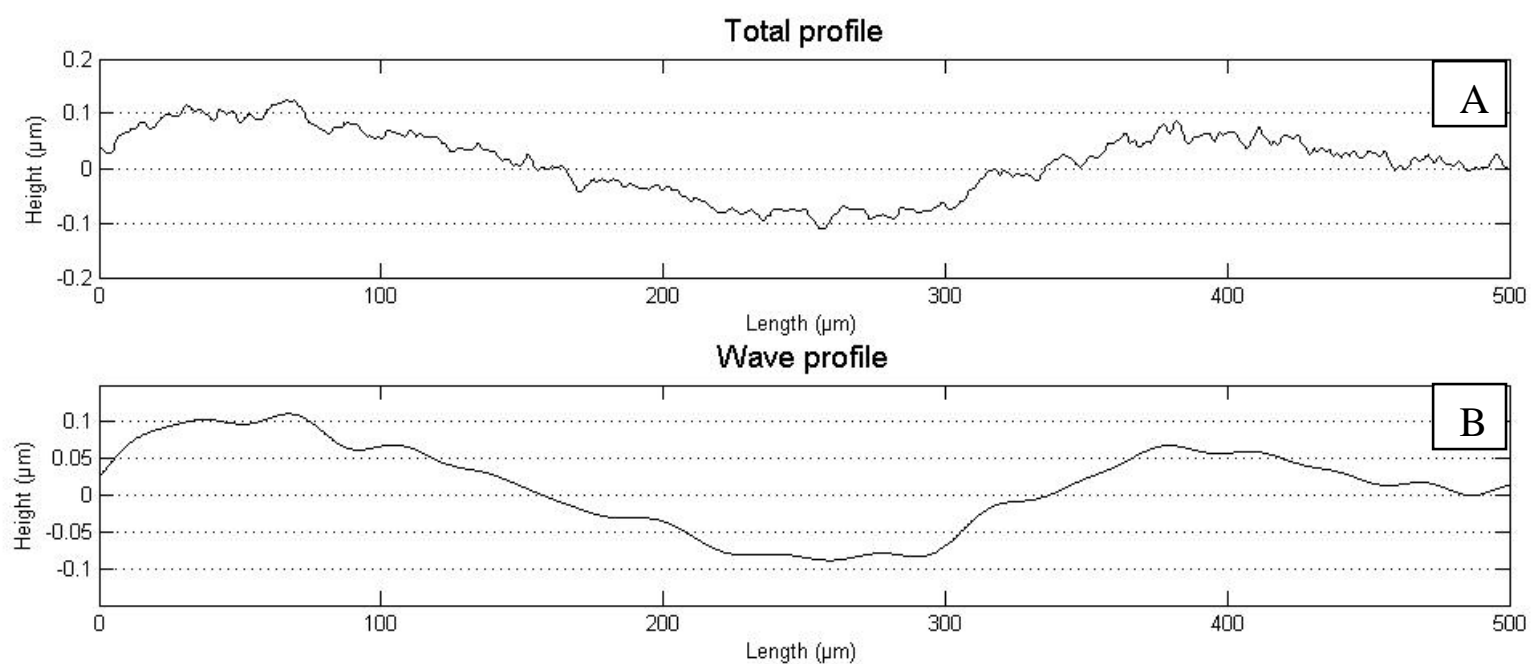

Roughness profile

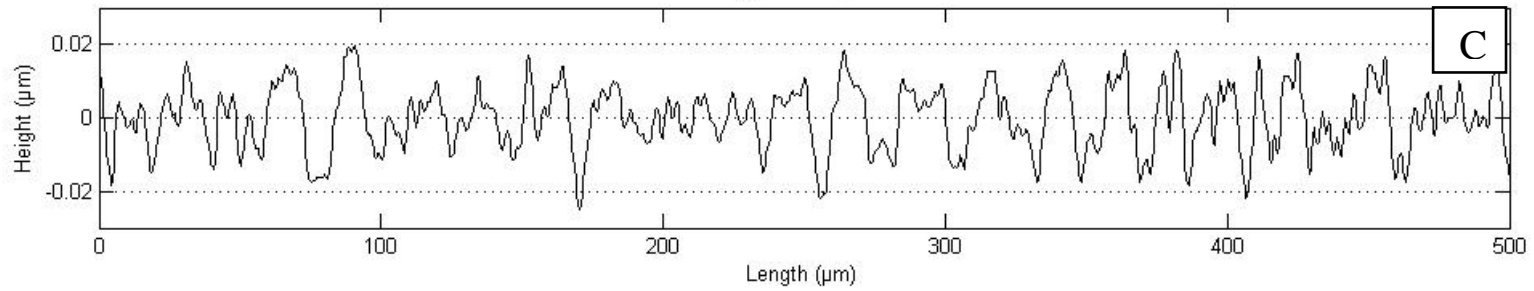

Fig. 14. Profilometry traces (working distance $=500 \mu \mathrm{m}$ ) of the etched membrane surface: $(\mathrm{A})$ total profile; (B) wave profile; (C) roughness profile (cut off $=80 \mu \mathrm{m}$ ) 


\begin{tabular}{|c|c|c|c|c|c|c|}
\hline & \multicolumn{3}{|c|}{ TFE } & \multicolumn{3}{c|}{ LFE } \\
\hline & $k^{(a)}$ & $k^{(b)}$ & $k^{(c)}$ & Max of $k^{(a)}$ & Max of $k^{(b)}$ & Max of $k^{(c)}$ \\
\hline$(100)$ cut & 0 & 0 & 0 & 0 & 6.66 & 6.66 \\
\hline$(110)$ cut & 0 & 6.66 & 0 & 4.25 & 0 & 0 \\
\hline$(111)$ cut & 4.76 & 0 & 0 & 0 & 4.6 & 4.6 \\
\hline (211) cut & 3.72 & 0 & 3.85 & 2.5 & 4.25 & 2.8 \\
\hline
\end{tabular}

Table 1: TFE and LFE coupling factors for the selected orientations of GaAs wafers.

\begin{tabular}{|l|c|c|}
\hline & $f_{R}(\mathrm{MHz})$ & $f_{R 3}(\mathrm{MHz})$ \\
\hline Analytical results & 33.53 & 100.23 \\
\hline FEM results & 33.45 & 100.30 \\
\hline$\Delta f_{R} / f_{R}(\%)$ & 0.3 & 0.007 \\
\hline
\end{tabular}

Table 2. Values of the resonance frequencies (in $\mathrm{MHz}$ ) as computed from equation (7) and as evaluated from FEM simulation.

\begin{tabular}{|l|c|l|c|}
\hline Process step & $\mathrm{N}^{\circ}$ & Composition of solutions & Etch rate $(\mu \mathrm{m} / \mathrm{min})$ \\
\hline Thinning & 1 & $1 \mathrm{H}_{2} \mathrm{SO}_{4}: 2 \mathrm{HCl}: 3 \mathrm{~K}_{2} \mathrm{Cr}_{2} \mathrm{O}_{7}$ & 1.2 \\
\hline & 2 & $1 \mathrm{H}_{2} \mathrm{SO}_{4}: 2 \mathrm{HCl}: 3 \mathrm{~K}_{2} \mathrm{Cr}_{2} \mathrm{O}_{7} /$ stirring & 2.8 \\
\hline & 3 & $1 \mathrm{H}_{3} \mathrm{PO}_{4}: 1 \mathrm{H}_{2} \mathrm{O}_{2}: 1 \mathrm{H}_{2} \mathrm{O}$ & 1.6 \\
\hline & 4 & $7 \mathrm{H}_{3} \mathrm{PO}_{4}: 5 \mathrm{H}_{2} \mathrm{O}_{2}: 8 \mathrm{H}_{2} \mathrm{O}$ & 4.58 \\
\hline & 5 & $1 \mathrm{H}_{3} \mathrm{PO}_{4}: 1 \mathrm{H}_{2} \mathrm{O}_{2}: \mathrm{CH} 3 \mathrm{OH}$ & 1.7 \\
\hline & 6 & $1 \mathrm{HNO}_{3}: 1 \mathrm{H}_{2} \mathrm{O}_{2}: 1 \mathrm{CH}_{3} \mathrm{COOH}$ & 6.4 \\
\hline & 7 & $1 \mathrm{HNO}_{3}: 1 \mathrm{H}_{2} \mathrm{O}_{2}$ & 8 \\
\hline Micromachining & 8 & $1 \mathrm{HNO}_{3}: 1 \mathrm{H}_{2} \mathrm{O}_{2}: 1 \mathrm{H}_{2} \mathrm{O}$ & 3.6 \\
\hline & 9 & $1 \mathrm{H}_{3} \mathrm{PO}_{4}: 9 \mathrm{H}_{2} \mathrm{O}_{2}: 1 \mathrm{H}_{2} \mathrm{O}$ & 14 \\
\hline
\end{tabular}

Table 3. Etching rates measured at a constant room temperature of $22^{\circ} \mathrm{C}\left(\mathrm{T}=\mathrm{T}_{22}\right)$. 


\begin{tabular}{|c|l|c|c|c|}
\hline $\mathrm{N}^{\circ}$ & \multicolumn{1}{|c|}{ Etchant } & $\mathrm{T}\left({ }^{\circ} \mathrm{C}\right)$ & $\mathrm{Ra}(\mathrm{nm})$ & Rms (nm) \\
\hline 1 & $1 \mathrm{H}_{2} \mathrm{SO}_{4}: 2 \mathrm{HCl}: 3 \mathrm{~K}_{2} \mathrm{Cr}_{2} \mathrm{O}_{7}$ & $\mathrm{~T}_{22}$ & 3.1 & 4.7 \\
\hline 2 & $\begin{array}{l}1 \mathrm{H}_{2} \mathrm{SO}_{4}: 2 \mathrm{HCl}: 3 \quad \mathrm{~K}_{2} \mathrm{Cr}_{2} \mathrm{O}_{7} / \\
\text { stirring }\end{array}$ & $\mathrm{T}_{22}$ & 4.1 & 6 \\
\hline 3 & $1 \mathrm{H}_{3} \mathrm{PO}_{4}: 1 \mathrm{H}_{2} \mathrm{O}_{2}: 1 \mathrm{H}_{2} \mathrm{O}$ & $\mathrm{T}_{22}$ & 1.8 & 2.4 \\
\hline 4 & $7 \mathrm{H}_{3} \mathrm{PO}_{4}: 5 \mathrm{H}_{2} \mathrm{O}_{2}: 8 \mathrm{H}_{2} \mathrm{O}$ & $\mathrm{T}_{22}$ & 0.96 & 1.31 \\
\hline 5 & $1 \mathrm{HNO}_{3}: 1 \mathrm{H}_{2} \mathrm{O}_{2}: \mathrm{CH}_{3} \mathrm{COOH}$ & $\mathrm{T}_{22}$ & 3.7 & 4.7 \\
\hline 6 & $1 \mathrm{HNO}_{3}: 1 \mathrm{H}_{2} \mathrm{O}_{2}$ & $10^{\circ} \mathrm{C}$ & 2 & 2.6 \\
\hline 6 & $1 \mathrm{HNO}_{3}: 1 \mathrm{H}_{2} \mathrm{O}_{2}$ & $\mathrm{~T}_{22}$ & 3.9 & 6.2 \\
\hline 7 & $1 \mathrm{HNO}_{3}: 1 \mathrm{H}_{2} \mathrm{O}_{2}: 1 \mathrm{H}_{2} \mathrm{O}$ & $\mathrm{T}_{22}$ & 2.4 & 3.0 \\
\hline 9 & $1 \mathrm{H}_{3} \mathrm{PO}_{4}: 9 \mathrm{H}_{2} \mathrm{O}_{2}: 1 \mathrm{H}_{2} \mathrm{O}$ & $\mathrm{T}_{22}$ & 2.85 & 3.55 \\
\hline
\end{tabular}

Table 4. Roughness parameters of (100) etched GaAs surfaces in several conditions of temperature (room temperature of $22^{\circ} \mathrm{C}$ or $10^{\circ} \mathrm{C}$ ) and stirring. 